\title{
Sustaining STEM Outreach: Successes and Challenges
}

\author{
Virginia L. Shepherd ${ }^{1,2}$, Jennifer A. Ufnar ${ }^{1,2}$, and Ann Chester $^{3}$ \\ ${ }^{1}$ Department of Teaching and Learning and ${ }^{2}$ Collaborative for STEM Education and Outreach, Vanderbilt University, Nashville, Tennessee; and ${ }^{3}$ Health Sciences and
}

Technology Academy, West Virginia University, Morgantown, West Virginia

Keywords: Commentary, STEM Outreach

Publication Date: August 10, 2020

DOI: https://doi.org/10.15695/jstem/v3i2.10

Our STEM workforce continues to fall short of the needs of our communities worldwide, both in its size and in its diversity. Over the past several decades, numerous U.S. Federal and international agencies have called for STEM experts to step up to the challenge to improve the workforce through STEM education reform by developing partnerships with their local K-12 community. Simultaneously, for years, STEM experts who develop such outreach programs have found a lack of platforms for publishing results and best practices from their work. Without peer reviewed literature sources providing proven practice guidance to new initiatives, progress is stifled. Thus, the Journal of STEM Outreach (JSO) was started in 2018 with a mission to provide a peer-reviewed source of research studies, case studies, and program descriptions of outreach programs that have worked. New investigators can use these published articles to design and implement effective programming based on partnerships with K-12 districts.

To dive even deeper into how successful some programs are in increasing STEM interest in diverse populations of underserved children and how they have been sustained over decades, we invited researchers to submit manuscripts for a special issue devoted to descriptions of programs that have positive outcomes and have continued at least eight years beyond federal funding. Abstracts from seventeen programs were accepted, and the first nine are included in this initial issue of the JSO "Special Issue on Sustained Outreach Programs." The articles published in this issue cover a broad range of topics, audiences, and STEM institutions. Some authors have chosen to highlight single programs such as the virtual Great Barrier Reef project in Australia and a high school internship program in San Francisco. Others have described the history and sustainability of centers with multiple programs such as the Life Sciences Learning Center from Rochester, NY; the Kansas K-12 Initiative to encourage students to continue STEM studies; and CityLab and MobileLab out of Boston. There are teacher professional development programs such as the Teacher Enrichment Initiative in San Antonio. The GEMS program at the Walter Reed Army Institute of Research partners STEM undergraduates with middle and high school students to increase learning through hands-on approaches, and the FoodMASTER program from Northern Illinois University provides lessons based on food and nutrition to enhance real-world science learning. The program out of the University of Nebraska has developed service-learning courses to connect STEM undergraduates with middle students.

Sustainability is perhaps the greatest challenge confronting those who develop outreach programs. As defined by Century and Levy (2004), sustainability is "The ability of a program to maintain its core beliefs and values and use them to guide program adaptations to changes and pressures over time." Outreach to the K-12 community is not the major focus of scholarly work at many of our universities, making it difficult for some to achieve sustainability. Battling barriers such as changes in university and/or K-12 leadership; shortage of funding; lack of support from one or more partners etc., it is remarkable that so many programs have survived, with several continuing for 20 years or more.

Recurring strategies have emerged for sustaining programs. For example, programs frequently rely heavily on partnerships with other organizations and individuals. These partnerships offer mentoring from formal and informal science education organizations. They include collaborations with strong scientist-educators who can provide interactive and engaging experiences for the participants. These partnerships often help the leadership develop curriculum tailored to specific educational goals within each grade level and take advantage of experts in the field who can communicate effectively with non-science audiences. These partnerships enhance investment and buy-in by community to increase diversity in the participating students. Beyond strategies involving partnerships, programs often develop multiple funding sources. A diverse portfolio of funding streams helps bridge gaps when one funding sources ends. Another strategy involves program leadership investing significantly in communicating the results of the efforts to multiple audiences to enhance interest and build relationships with important stakeholders. Last but not least, often these programs are low cost for high benefit to students. While this 
list of strategies is not exhaustive, it does include the most common strategies employed by the successfully sustained programs in this issue.

As we continue at this point in time with the tragedy of a pandemic, many programs have been forced to alter their approaches since in-person teacher and student projects are not allowed now and many will be shut down for this coming year. Recognizing that this situation will not last forever AND will produce new ways of doing things that will become the new normal, the co-editors of the JSO feel it is even more important to seize this opportunity to chronicle what has worked providing a foundation from which to test the innovations emerging from the pandemic. We recently developed a survey to determine how outreach directors are handling the virtual-only mandate, and if these new strategies will continue beyond the closing down of in-person programs. Very early results suggest that many programs have quickly adapted to the virtual platform. For example, teacher PD, student focus groups, and student journal clubs are now conducted via Zoom. Science clubs have been adapted to unique online environments; lessons are being taught through game-based strategies; students and teachers can view simulations via YouTube channels; several programs are developing STEM curricula that can be delivered virtually; and one program is working with teachers to help them adapt their teaching to an online format. As we move to what will be a "new normal" in STEM education, it is imperative that we continue to adapt and evolve such that our programs will provide our partners with creative, unique, engaging, and sustainable approaches to learning.

\section{REFERENCE}

Century, J.R., and Levy, A.J. (2004). Bringing theory of and research on sustainability to practice: Giving school improvement a "bottom line." Paper presented at The Scale Think Tank. November 2003. 